\title{
Theoretical and experimental researches to ascertain the strength and best form of iron beams
}

\section{Eaton Hodgkinson}

To cite this article: Eaton Hodgkinson (1832) Theoretical and experimental researches to ascertain the strength and best form of iron beams, Philosophical Magazine Series 3, 1:3, 207-208, DOI: $10.1080 / 14786443208647875$

To link to this article: http://dx.doi.org/10.1080/14786443208647875

曲 Published online: 01 Jun 2009.

Submit your article to this journal $[\pi$

Џll Article views: 2

Q View related articles $\sqsubset$ 
friendly feeling towards him; and although an entire stranger to us, we wish him every success in his laudable endeavour to build up an honourable reputation for himself: yet we earnestly counsel him not again to attempt the destruction of that of his neighbour; as it betrays both bad taste and bad feeling, and may eventually convert into personal enemies those who might otherwise become useful friends.

On Suspension Bridges; containing an Inquiry into the proper Forms of their Catenaries; with Remarks on the Menai Bridge, and that at Broughton; as likewise some Account of the Failure of the latter. By Eaton Hodgrinson, Manchester, 1831.

In the eastern parts of the world, rope and chain bridges of large span have for a long period been in use; but in Europe the adoption of bridges of suspension is of comparatively modern date, and has opened a new and interesting field for inquiry and experiment, both for the engineer and the mathematician, and has rendered of practical importance the theory of the catenarian curve. During the last century, mathematicians investigated many of the properties of this curve; but the addition of the materials which are necessary to form the roadway, and to insure sufficient strength for the variable and large loads of transit, have added new data to the problem.

Mr. Eaton Hodgkinson has, in the present treatise, given a very clear abstract of the properties of this curve under all the probable variations it is liable to in its application to bridges of suspension; not only when the substance of the chain is of uniform strength, but also when the strength varies as the strain,-concluding with an example upon assumed data.

The neat and elegant manner observed throughout renders the tract a desirable object in the library of the practical engineer.

The second part of the work contains an account of the chain bridge at Broughton, near Manchester, with a particular estimate of the strain upon the various parts as compared with the strength, and aiso some important information on the form of the joints of the links ; to which are added some observations on high tests, and on defective welding of the bars.

Next follow a few remarks on the Menai Bridge, showing that it possesses sufficient strength to support seven times its own weight.

An Appendix is given, containing remarks and observations on the cause of failure of the bridge at Broughton, after standing some years, but which has since been repaired and made more secure*.

Theoretical and Experimental Researches to ascertain the Strength and best Form of Iron Beams. By the same Author.

The builder and engineer will find in this treatise many important experiments, conducted with great skill, and described with accuracy of detail. It should be read by every person who intends to use iron beams. The author has long been known for his abilities as a mathematician, and his application of those abilities to practical purposes.

* An account of the fall of the Broughton Suspension Bridge, with some particulars of the causes of its failure, were given in Phil. Mag. and Annals, N.S. vol. ix. p. 384. 
The use of iron for beams has been lately much and deservedly resorted to. In the application of a new material it is to be expected that there will be occasional failures, partly owing to motives of oconomy, and partly to want of skill in the builder. The price of iron renders it desirable that the smallest quantity should be used which is consistent with safety and durability.

There are several popular treatises on the strength of iron and the form of beams; but the rules contained in them are frequently at variance with experiments, and therefore mislead the practical man, who has not leisure or ability to investigate the principles upon which they are founded.

In this tract, the author investigates the theory of strength, and of resistance to fracture and deflection, and supplies by judicious experiments the defective elementary data, giving the particulars at large of numerous experiments on iron of various forms and dimensions, so as to enable a practical builder to satisfy his own mind of the ground upon which the deductions are made. These experiments prove that the form recommended by the late Mr. Tredgold is inferior to others which have since been adopted, and also that the formula given by $\mathrm{Mr}$. Tredgold for determining the strength is incorrect, and may lead to serious errors*.

Much of the work is occupied by the subject of the transverse strength and strain, and some useful deductions are made on the ultimate deflection, - a point which at present deserves further investigation.

The author acknowledges his obligations to Messrs. Fairbairn and Lillie for the assistance they rendered him at their foundry, by which he was enabled to adopt a scale of dimensions seldom within the means of a theoretical investigator. Instances of liberality of this kind are frequently met with in this country, much to the honour of the persons who thus manifest themselves friends to their country and to science.

The result of Mr. Hodgkinson's experiments on cast iron beams having the bottom rib containing more than half the matter of the whole beam, shows that the breaking weight was proportionate to the area of the bottom rib, and to the full depth of the beam, and inversely as the length, subject to a constant factor depending on the position of the beam in the casting, the vertical castings being about ${ }_{-1}^{-1}$ th stronger than the horizontal castings; the quality of the metal will also modify the factor in some degree. In such important experiments as these, the determination and statement of the specific gravity and hardness, together with the modulus of elasticity of the material, would add to their value, with very little additional burden to the operator.

On the Economy of Machinery and Manufactures. By Caardes BABbage, Esq. A.M., Lucasian Professor of Mathematics in the University of Cambridge, and Member of several Academies. London, 1832.

Although the present volume does not properly come within the sphere of a scientific Journal, yet the principles which it discusses

* Analyses of the first and second editions of Mr. Tredgold's Essay on the Strength of Cast Iron, will be found in Phil. Mag. vol. lx. p. 137; and vol. Ixiii. p. 52. 